\title{
EVENTOS NOTICIADOS SOBRE O IRB BRASIL RESSEGUROS S.A. E OS EFEITOS NO SEU VALUATION
}

\section{EVENTS REPORTED ABOUT IRB BRASIL RESSEGUROS S.A. AND THE EFFECTS ON ITS VALUATION}

\author{
LAUREN DAL BEM VENTURINI \\ Universidade Federal de Santa Catarina - UFSC \\ Mestre em Contabilidade (UFRGS). Doutoranda em Contabilidade (UFSC) \\ Orcid: http://orcid.org/0000-0003-4185-9842 / E-mail: laurenventurini@hotmail.com \\ Universidade Federal de Santa Catarina, Programa de Pós-Graduação em Contabilidade - PPGC \\ Centro Socioeconômico - CSE, Bloco F, Campus Trindade, CEP 88040-970 - Florianópolis, SC \\ LEONARDO FLACH \\ Universidade Federal de Santa Catarina - UFSC \\ Professor da graduação e pós-graduação em Contabilidade (UFSC) \\ Pós-doutor em Contabilidade e Finanças pelo Massachusetts Institute of Technology (MIT/EUA) \\ Doutor em Administração pela Universidade Federal do Rio Grande do Sul (UFRGS) \\ Orcid: http://orcid.org/0000-0002-4316-0704 / E-mail: leonardo.flach@gmail.com \\ JONATAS DUTRA SALLABERRY \\ Universidade Federal de Santa Catarina - UFSC \\ Doutorando em Contabilidade (UFSC) \\ Orcid: http://orcid.org/0000-0001-7492-727X / E-mail: jonatas.sallaberry@hotmail.com

\section{LUÍSA KARAM DE MATTOS} \\ Universidade Federal de Santa Catarina - UFSC \\ Doutoranda no Programa de Pós-Graduação em Administração (UFSC) \\ Orcid: http://orcid.org/0000-0003-1990-3034 / E-mail: luisakmattos@gmail.com \\ Submissão: 11/03/2021. Revisão: 03/09/2021. Publicação: 21/10/2021. \\ DOI: http://dx.doi.org/10.22277/rgo.v14i3.6165
}

\section{RESUMO}

O manuscrito tem o propósito de desenvolver conhecimentos e ilustrar a discussão sobre eventos relacionados aos impactos de práticas contábeis, informações noticiadas e da Covid19 no valuation de uma empresa, o IRB Resseguros, buscando aprimorar o senso crítico sobre erros e acertos protagonizados pelas companhias e que influenciam no seu valuation. Por meio de um estudo exploratório e apresentado como caso de ensino, que permite maior significância para o processo de aprendizado do aluno, relata que entre a oferta pública de ações - IPO (2017) e o encerramento de 2019, as ações do IRB chegaram a subir $337 \%$, mas em maio de 2020 as ações recuaram abaixo do seu IPO. Concomitante aos efeitos econômicos da Covid-19, uma gestora de investimentos apresentou carta questionando as práticas contábeis e indicando que a rentabilidade do negócio seria muito menor do que o conhecido, além de outros eventos adversos. Para o IRB, as alegações sobre o desempenho revelariam simples "prejuízo contábil", advindo da elevação do dólar causada pela Covid-19 e consequente retração econômica. O caso de ensino apresenta discussões que contribuem

Este é um artigo publicado em acesso aberto (Open Access) sob a licença Creative Commons Attribution, que permite uso, distribuição e reprodução em qualquer meio, sem restrições desde que o trabalho original seja corretamente citado. 
para a avaliação sistêmica dos impactos de eventos adversos nas organizações e seu valuation. $\mathrm{O}$ caso IRB discute premissas envolvidas no processo de avaliação de empresas, para tanto, considera eventos contingenciais, particularidades setoriais, macroeconômicos, decisões estratégicas, relatórios administrativos e financeiros e notícias sobre a empresa. Este case contribui com discussões práticas para o contexto de investidores, do mercado de capitais e de avaliação de empresas.

Palavras-chave: Valuation. IRB. Governança.

\begin{abstract}
The manuscript has the purpose to develop knowledge and illustrate the discussion of events related to the impacts of accounting practices, reported information and the Covid19 on a company's valuation, the IRB Resseguros, seeking to improve the critical sense about mistakes and successes carried out by companies and that influence their valuation. Through an exploratory study and presented as a teaching case, which allows greater significance for the student's learning process, reports that between the public offering of shares - IPO (2017) and the end of 2019, the IRB's shares reached rise 337\%, but in May 2020 the shares fell below their IPO. Concomitant to the economic effects of Covid-19, an investment manager company presented a letter questioning accounting practices and indicating that the profitability of the business would be much lower than known, in addition to other adverse events. For the IRB, the claims about performance would reveal a simple "accounting loss", arising from the rise in the dollar caused by Covid-19 and the consequent economic downturn. The teaching case presents discussions that contribute to the systemic assessment of the impacts of events on organizations and their valuation. The IRB case discusses assumptions involved in the company valuation process; therefore, it considers contingency events, sectorial, macroeconomic peculiarities, strategic decisions, administrative and financial reports, and news about the company. This case contributes to practical discussions in the context of investors, the capital market and company valuation.
\end{abstract}

Keywords: Valuation. IRB. Governance.

\title{
1 INTRODUÇÃO
}

A síndrome aguda respiratória denominada Coronavírus ou Covid-19 foi identificada de forma pública em dezembro de 2019, em Wuhan - China (Deng \& Peng, 2020). A Covid19 transmitida entre humanos avançou rapidamente. Detectada em outros países em janeiro de 2020, foi classificada como pandemia em março pela Organização Mundial de Saúde (OMS).

Nesse contexto de incerteza, o IRB Brasil Resseguros S.A. (IRB), empresa seguradora e resseguradora líder no segmento oferecendo cobertura para grandes riscos em diversas linhas de negócios, preparava-se para divulgar seu resultado ao mercado. Em 17 de fevereiro de 2020, segunda-feira, o CEO do IRB reuniu-se com o CFO e o diretor de relações com investidores para revisar o desempenho auditado de 2019, a ser anunciado ao mercado no dia seguinte.

Essa apresentação era esperada com ansiedade e expectativa sobre como o mercado reagiria às informações divulgadas, especialmente os investidores, e, por consequência o preço das ações. Para os diretores do IRB, o resultado da empresa em 2019 havia sido bom e 
Lauren Dal Bem Venturini, Leonardo Flach, Jonatas Dutra Sallaberry e Luísa Karam de Mattos

confiavam que o valor das ações seria apreciado após a divulgação dos relatórios financeiros.

No entanto, após sucessivos eventos, o mercado não reagiu conforme esperado. Da abertura do Pregão em 18 de fevereiro até 15 de maio, o IRB perdeu mais de 81,5\% do seu valor de mercado. Entre as reações adversas, as primeiras ocorreram ainda antes da divulgação dos resultados, e foi provocada por questionamento da gestora Squadra sobre as práticas de escrituração realizadas pela companhia, ao revelar que a rentabilidade seria muito menor do que grande parte do mercado acredita que foi seguida por outros fatos que causaram apreensão nos investidores e choques no mercado.

Em maio de 2020, a Superintendência de Seguros Privados (Susep) decidiu instaurar fiscalização especial na companhia, devido aos ativos garantidores de provisões técnicas estarem abaixo do mínimo regulatório. De acordo com o IRB, a situação seria decorrente do cenário causado pela Covid-19, com efeitos cambiais nas provisões técnicas expostas em moeda estrangeira, e com o aumento das provisões de sinistros a liquidar.

Diante da alta volatilidade do preço das ações da companhia e do excelente histórico de rentabilidade, os dirigentes do IRB manifestaram confiança nos fundamentos da empresa e discordância à Susep por não aceitar determinados ativos para cobrir passivos regulatórios. Portanto, estariam os dirigentes argumentando que esse efeito na posição patrimonial da empresa seria "meramente prejuízo contábil" sem relação com a saúde do negócio (Sescon/RJ, 2020).

\section{IRB BRASIL RESSEGUROS S.A.}

O Instituto de Resseguros do Brasil foi criado em 1939 com a missão de reter no país os riscos de empresas nacionais que antes eram transferidos para seguradoras no exterior. Em termos gerais, o resseguro é o seguro das seguradoras, pelo qual o ressegurador assume o compromisso de indenizar a seguradora por sinistros decorrentes de suas apólices.

Em 1960, com a criação do Sistema Nacional de Seguros Privados, o IRB passou a ser regulador do mercado de resseguro, e em 1996 foi transformado em sociedade de economia mista - IRB Brasil Resseguros S.A. O IRB manteve seu monopólio até 2007, quando a legislação foi alterada, passando a Susep a assumir a regulação e o IRB a ser um ressegurador local, reabrindo o mercado ressegurador. Em 1 ㅇ de outubro de 2013, o IRB foi privatizado, e em 2017 concluiu a oferta pública de ações (IPO) no Novo Mercado da Brasil, Bolsa, Balcão (B3), nível máximo de governança.

Após um ano como companhia aberta, as ações do IRB apresentaram a maior valorização em 2018, no IBrX 100 - índice das 100 ações de maior negociabilidade e representatividade do mercado de ações brasileiro. Além disso, assumiu a 8a posição entre as 10 maiores resseguradores do mundo, em valor de mercado. Em 2019 realizou dois dos mais bem-sucedidos follow-ons da B3, no valor aproximado de R\$ 10 bilhões, se tornando uma Corporation (empresa de capital difuso e sem acionista controlador).

O IRB possui mais de 80 anos de atuação, sendo considerado especialista no mercado, cuja tradição é fonte de confiança para todo o segmento de seguro e resseguro no país. Dispõe de equipe com vasto conhecimento e know-how nas diversas modalidades, atendendo as mais variadas demandas do mercado. Possui negócios em diversos países ao redor do mundo, com foco especial na América Latina, onde as atividades estão em expansão, dispondo de escritórios em Buenos Aires, Londres, São Paulo e a sede no Rio de Janeiro. 
As receitas do IRB advêm dos prêmios que ela retém menos os custos de sinistros que ela precisa pagar para as suas apólices. Outra receita é a financeira, denominada float, decorrente dos prêmios adiantados pelos clientes, aplicados em renda fixa, segundo as regras do Brasil. Geralmente, os contratos são anuais e esse ciclo vai se renovando, bem como novos clientes vão surgindo. Se a seguradora consegue precificar (subscrever) bem seu risco e as suas despesas operacionais (administrativas e de pessoal), o float pode até ficar com a seguradora.

A linha de negócios contempla seguros de riscos aeronáuticos, de engenharia, linhas financeiras, óleo e gás, property, responsabilidade civil, riscos rurais, transportes e marítimos, vida e previdência, de garantia e riscos diversos. A estrutura acionária possui free float (ações em circulação) de $98,7 \%$, sendo que seus principais investidores, em junho de 2020, são os da Tabela 1.

Tabela 1 - Acionistas com participação relevante no IRB

\begin{tabular}{c|c}
\hline Acionista & Participação (\%) \\
\hline Bradesco Seguros & 15,2 \\
\hline Itaú Seguros & 11,1 \\
\hline BlackRock & 5,1 \\
\hline Total & $\mathbf{3 6 , 7}$ \\
\hline
\end{tabular}

Fonte: IRB Brasil RE (2020).

O relatório da administração de 2019 relata um cenário de mudança do mercado segurador a partir de novas tecnologias e novos comportamentos do consumidor. O IRB sinaliza investimentos em inovação, com ênfase em transformação digital para retorno em médio e longo prazo. Além do mais, destacou ser uma empresa ágil para criar produtos e serviços, visando desenvolver o negócio de seguros, como opção para fintechs, construtechs, healthtechs, logtechs e big techs.

Nessa direção, subscreveram ações da B3i que é uma das iniciativas globais de desenvolvimento de novas tecnologias para o setor, incluindo o registro dos contratos de seguros por meio de uma plataforma blockchain. O IRB revelou perspectivas positivas para 2020, especialmente no agronegócio devido ao aumento de $150 \%$ no subsídio do governo para o seguro rural. Também destacou crescimento no setor de óleo e gás, que apresentava desempenho acima do Produto Interno Bruto (PIB). A eliminação da obrigatoriedade de apólices anuais de seguros foi apontada como uma oportunidade de novos negócios com a oferta de apólices flexíveis, válidas por meses, dias, ou outros critérios.

\section{REUNIÃO DE ANÁLISE FINANCEIRA DO EXERCÍCIO DE 2019}

No dia 17 de fevereiro de 2020, após aprovação das demonstrações contábeis pelo Conselho de Administração, conjectura-se que o Presidente (CEO) reúna-se com o diretorfinanceiro (CFO) e o diretor de relações com investidores (RI) para uma breve revisão do desempenho do IRB no ano de 2019, antes da divulgação ao mercado, que seria no dia seguinte. Para ambientação dos resultados financeiros do exercício de 2019 do IRB (Anexos 1 a 4), e para melhor aproveitamento didático, apresenta-se um diálogo simulado e dramatizado entre as partes com narrativas fictícias e adaptando alguns cargos dos personagens para a preservação da identidade pessoal.

CEO: convoquei essa reunião para fazermos uma última análise do nosso desempenho econômico-financeiro de 2019, a fim de equacionar o conhecimento entre os diretores, pois amanhã os relatórios serão disponibilizados ao mercado. 
RI: gostei de termos marcado essa reunião. Tenho algumas dúvidas, qual foi o comportamento do volume total de prêmios emitidos?

CFO: emitimos em 2019 o total de R\$ 8,5 bilhões em prêmios, 22,3\% acima do registrado em 2018. Desse total, $R \$ 4,8$ bilhões foram emitidos no Brasil (56,75\%) e $R \$ 3,6$ bilhões no exterior (43,3\%), avançando a emissão no Brasil em 14,4\% em relação a 2018. Esse aumento se deve ao segmento patrimonial, que corresponde a $33 \%$ no total, bem como a linha de negócios rural (23\%) e aos riscos especiais (14\%). Já o total de prêmios emitidos no exterior cresceu $34,4 \%$, com destaque para o segmento vida, o qual assumiu a liderança, com $37 \%$ do volume total, seguido do patrimonial (25\%) e rural (19\%), os quais são os mesmos setores em que a Companhia tem expertise em sua atuação local.

RI: obrigada pela clara exposição. Também recebo muitas dúvidas sobre o índice de retrocessão da companhia. Como foi a evolução desse indicador?

CEO: esse índice eu acompanho constantemente. Ele foi de 25,9\%, em 2019, e de $26,9 \%$ em 2018 , ou seja, houve recuo de $1 \%$. A diminuição no custo, com a manutenção de cobertura dos valores ressegurados foi possível em função da confiança dos retrocessionários no bom histórico de sinistralidade apresentado pela Companhia e pela melhoria da governança com a mudança para Corporation. Historicamente, tivemos redução relevante nesse índice, passou de 30,0\%, em 2017, para 25,9\%, em 2019, uma redução de $4,1 \%$.

RI: comentamos sobre o comportamento do total de prêmios emitidos e os retidos?

CFO: o total de prêmios retidos foi da ordem de $\mathrm{R} \$ 6,3$ bilhões no encerramento de 2019, frente a, aproximadamente $\mathrm{R} \$ 5,1$ bilhões no ano anterior, representando um crescimento de 23,08\%. Já o total de prêmios ganhos foram de $\mathrm{R} \$ 5,6$ bilhões em 2019, representando um crescimento de 18,3\% em relação a 2018.

RI: poderiam comentar sobre o nosso resultado financeiro e lucro do exercício?

CFO: bem, quanto ao nosso resultado financeiro consolidado (Anexo 1), controladora e suas subsidiárias/sucursais, tivemos expansão de 16,6\%, foi de $R \$ 733,5$ milhões em 2019, ante $\mathrm{R} \$ \mathbf{6 2 8 , 9}$ milhões em 2018. Esse desempenho é decorrente, especialmente, de alocações estratégicas realizadas em títulos públicos pré-fixados e indexados à inflação, que foram impactados positivamente por conta do fechamento das taxas de juros em 2019, bem como operações táticas cambiais e em renda variável.

CEO: estou muito orgulhoso de nosso lucro líquido. Registramos expansão de $44,7 \%$ em relação a 2018, passando de $\mathrm{R} \$ 1,2$ bilhão para $\mathrm{R} \$ 1$ 1,7 bilhão. Nossa distribuição de dividendos e juros sobre o capital próprio (JCP), proposta pela administração para o exercício de 2019 totalizou R\$ 1,2 bilhão, o que representa 71\% do lucro líquido registrado no período. Do montante aprovado de JCP de R\$ 257,3 milhões, $R \$ 198,5$ milhões foram pagos antecipadamente no mês de novembro de 2019. Assim, o montante pago em dividendos somou $\mathrm{R} \$ 959,8$ milhões. Eu sei que tivemos um crescimento de $24,1 \%$ sobre o ano anterior das despesas gerais e administrativas, que somaram em 2019 o valor de $\mathrm{R} \$$ 283,1 milhões, mas, o principal fator a impactar isso foi o incremento em benefício pósemprego.

CFO: entendo que outra conquista é a boa apreciação de nossas ações no mercado de capitais. Valorizaram-se $44,4 \%$ em 2019 , em comparação a uma alta de $31,58 \%$ do Ibovespa, que é o principal índice da bolsa. De 28 de dezembro de 2018 a 30 de dezembro de 2019, as ações do IRB (B3: IRBR3) atingiram um volume médio diário negociado de R\$ 176 milhões. No dia 30 de dezembro de 2019, o valor de mercado da Companhia era de $\mathrm{R} \$ 36,5$ 
bilhões, comparado a R\$ 8,5 bilhões na abertura de capital em 31 de julho de 2017. Entre o IPO e o encerramento de 2019, as ações do IRB apresentaram uma apreciação de $337 \%$.

RI: realmente, alcançamos um bom resultado em 2019. Amanhã, com a divulgação desses números ao mercado, acredito que teremos mais movimentações de compra de ações. Além do mais, iremos esclarecer que não há problemas com nosso resultado econômico-financeiro, conforme questiona a gestora Squadra no documento de 154 páginas enviado no dia 2 de fevereiro e, reenviado no dia 9 de fevereiro, que provocou queda no valor de nossas ações. Eles alegam que há indícios que apontam lucros normalizados (recorrentes) significativamente inferiores aos lucros contábeis reportados nas demonstrações financeiras.

CEO: nossos resultados foram auditados por uma firma auditora big four, além do mais, nossa companhia está listada no mais elevado nível de governança da B3. Temos que lembrar que a Squadra, como gestora de recursos e fundos, montou uma posição short, que aluga ações e em seguida as vendem com o objetivo de recomprá-las no futuro a um preço mais baixo. Então, eles montaram uma posição que lucra quando o preço da nossa ação cai.

CFO: nossas Demonstrações Contábeis consolidadas foram preparadas conforme as práticas adotadas no Brasil. Entendo que, talvez seja "meramente prejuízo contábil", em especial, dos efeitos da variação cambial sobre as provisões técnicas da companhia em moeda estrangeira, tendo em vista o cenário causado pelo Covid-19, bem como do aumento das provisões de sinistros a liquidar no primeiro quadrimestre de 2020. Enfrentamos outro conflito que é a Susep não aceitar determinados ativos para cobrir os nossos passivos regulatórios. Estou confiante que a divulgação dos resultados de 2019, esclarecerá ao mercado sobre o nosso bom desempenho e nossas ações voltarão a subir.

\section{CARTAS DA SQUADRA E OUTROS FATOS QUE PROVOCARAM A QUEDA DAS AÇÕES DO IRB}

Em meio à preparação do IRB para divulgar seu resultado financeiro de 2019 ao mercado, um encadeamento de eventos noticiados pela empresa ou outros meios de comunicação, no período de fevereiro a maio de 2020, provocou muita repercussão entre os investidores, ocasionando forte queda das ações.

Antes disso, em novembro de 2019, a gestora Squadra elaborou uma primeira análise sobre o IRB, bastante completa. Essa avaliação foi enviada à Susep, à CVM e à própria empresa. Inquietos com a resposta enviada pelo IRB em 26 de novembro de 2019, a gestora divulgou mais duas cartas questionando o IRB justamente quando ele estava em período de silêncio devido à divulgação do resultado do quarto trimestre de 2019, que somente viria a ser publicado no dia 18 de fevereiro de 2020. A segunda carta, com 154 páginas, foi divulgada no dia 2 de fevereiro, um domingo, o que levou as ações da empresa de resseguros a fecharem em queda de $9,1 \%$ na segunda-feira. Por meio de análise técnica e detalhada, a Squadra entende que o IRB teve lucro, contudo muito menor do que o mercado acredita ser. Desta forma, os principais pontos da análise da Squadra em 2 de fevereiro são:

a) Divergência na informação que as seguradoras brasileiras reportam de sinistros que elas recuperaram do IRB em relação ao que o IRB demonstra como despesa de sinistro. Em tese, a Squadra aponta que as seguradoras estão recuperando muito mais recursos do que o IRB evidencia em sua DRE;

b) Envolvimento em contratos originados em licitações públicas de sinistralidade elevada (índice de perdas nas suas apólices); 
c) Registro na DRE de redução das despesas de sinistro com base em custos não realizados. Em suma, a companhia reduziu provisões antigas, porque espera receber futuramente vários processos na justiça, aumentando o lucro;

d) Reporte de resultados não recorrentes (efeitos extraordinários), mas que não possuem impacto real no caixa da empresa, beneficiando o lucro da empresa;

e) Geração de caixa muito abaixo do esperado e, acúmulo de recebíveis. Assim, comparando o período entre 2014 e 2019, a Squadra revela não compreender o destino do dinheiro, pois há elevação dos recebíveis, redução do caixa em quase metade e evidência de lucros recorrentes com distribuição de dividendos. Com isso, o alto retorno sobre patrimônio líquido (ROE) não seria sustentável no longo prazo;

f) Resultado financeiro favorecido por conta da venda de ativos antigos com custos defasados no balanço pela longa data.

A partir da recorrência do questionamento sobre o resultado líquido, o risco de investimento nas ações do IRB aumentou significativamente, pois a Companhia não prestou esclarecimentos suficientes que permitissem refutar os argumentos da Squadra. O IRB acusou a Squadra de aumentar a posição em um terço, pouco antes da divulgação do relatório, o que, segundo reclamação apresentada à CVM, seria uma negociação atípica configurando "insider trading", pois quanto menor a cotação das ações do IRB, maior seria o lucro da gestora.

Em 4 de fevereiro, O Globo divulga esses fatos e indica que o IRB contratou renomados contadores professores que emitiram pareceres da não identificação de irregularidades nas demonstrações da resseguradora. A gestora decidiu publicar um novo documento, no qual responde ao comunicado do IRB e sustenta todos os ajustes indicados no balanço. Assim, a "tréplica" com 50 páginas também foi publicada em um domingo, 9 de fevereiro, que foi sucedida de teleconferências privadas promovidas pelo IRB com analistas e clientes de bancos de investimentos para rebater os argumentos da Squadra. Ainda assim, nesse dia 10 de fevereiro, o preço das ações caiu 16,5\%. Em 18 de fevereiro, o IRB divulgou os resultados do quarto trimestre de 2019, e também se identifica a informação de que teria contratado uma auditoria independente para avaliar especificamente os números atuarias da empresa (InfoMoney, 2020a).

No dia 27 de fevereiro, entre notícias e teleconferências tratando sobre a renúncia do presidente do Conselho de Administração, e de suspeitas de fraudes contábeis, surge reportagem do Estadão de que Warren Buffett teria triplicado sua posição nas ações do IRB, causando alta de quase $10 \%$ no fechamento do preço das ações. No dia seguinte, o IRB divulgou comunicado sobre a renúncia do presidente do Conselho de Administração sem explicar os motivos, ampliando a desconfiança do mercado. Em 3 de março, o IRB divulgou ter verificado a posição das ações em 27 de fevereiro e que Buffett não deteria o capital mínimo de 5\% (InfoMoney, 2020). Nesse mesmo dia Buffett se manifestou relatando que não foi acionista do IRB e tampouco teria intenção de ser. A desconfiança do mercado financeiro, somado aos comunicados do IRB e de Buffett resultou em uma forte queda de $41 \%$ no preço das ações nesse dia.

No dia 11 de maio, a Susep instaurou fiscalização especial para apurar uma insuficiência na composição dos ativos garantidores de provisões técnicas e, consequentemente, de sua liquidez regulatória, causando queda de quase $15 \%$ no valor das ações do IRB. Para a companhia, a decisão da Susep não afeta a administração regular dos seus negócios, alegando ser consequência, principalmente, da variação cambial nas 
provisões técnicas em moeda estrangeira, causada pelo cenário pandêmico do novo coronavírus.

O avanço da pandemia tem gerado previsões econômicas pessimistas, com retração de negócios e, principalmente pelos reflexos cambiais da Covid-19, em especial, em relação às moedas mais fortes. A variação cambial de passivos expostos a essa influência afeta o resultado da seguradora e pode causar aumento das provisões de liquidação de sinistros.

A despeito das influências macroeconômicas da Covid-19 nas demonstrações financeiras, em 21 de maio, o diretor da controladoria do IRB foi demitido por justa causa devido "fraude em contratos", ampliando a preocupação dos investidores. Nesse contexto de eventos, o preço da ação do IRB, que atingiu, em janeiro de 2020 , o valor de $R \$ 44,83$, registrou no final de maio de 2020, valor de $R \$ 8,30$, abaixo do seu IPO (R\$ 27,24 em julho de 2017). Os reflexos nas ações da empresa são apresentados na Tabela 2, em ordem cronológica, comparativamente aos resultados do segmento financeiro (IFNC), o qual participa o IRB, e do índice da B3 (BVSP), a fim de permitir a percepção sobre a variação possivelmente não relacionada aos eventos da organização.

Tabela 2 - Síntese e reflexos dos principais eventos noticiados sobre o IRB

\begin{tabular}{|c|c|c|c|c|}
\hline Evento & Data & IRBR3 & IFNC & BVSP \\
\hline Squadra Investimentos compartilha análises com o IRB & $01 / 11 / 19$ & $1,49 \%$ & $0,35 \%$ & $0,91 \%$ \\
\hline IRB responde à Squadra Investimentos & $26 / 11 / 19$ & $-1,58 \%$ & $-2,11 \%$ & $-1,26 \%$ \\
\hline Squadra Investimentos divulga Relatório de sua análise sobre o IRB & $02 / 02 / 20$ & $-*$ & $-*$ & $-*$ \\
\hline Segunda-feira, pós relatório da Squadra & $03 / 02 / 20$ & $-9,06 \%$ & $0,32 \%$ & $0,76 \%$ \\
\hline $\begin{array}{l}\text { O Globo reporta que pareceres de renomados contadores } \\
\text { professores não encontraram irregularidades nas demonstrações } \\
\text { contábeis }\end{array}$ & $04 / 02 / 20$ & $1,30 \%$ & $0,06 \%$ & $0,81 \%$ \\
\hline Squadra Investimentos divulga esclarecimentos & $09 / 02 / 20$ & $-*$ & $-*$ & $-*$ \\
\hline IRB convida para teleconferências extraordinárias & $10 / 02 / 20$ & $-16,50 \%$ & $-0,54 \%$ & $-1,05 \%$ \\
\hline Véspera da divulgação do 4 o trimestre & $17 / 02 / 20$ & $5,62 \%$ & $0,19 \%$ & $0,81 \%$ \\
\hline IRB divulga resultado do 4 o trimestre & $18 / 02 / 20$ & $-0,81 \%$ & $-0,06 \%$ & $-0,29 \%$ \\
\hline $\begin{array}{l}\text { Estadão publica que a Berkshire Hathaway (empresa de Warren } \\
\text { Buffett) amplia participação na IRB }\end{array}$ & $27 / 02 / 20$ & $6,67 \%$ & $-0,85 \%$ & $-2,59 \%$ \\
\hline IRB comunica renúncia do Presidente do Conselho & $28 / 02 / 20$ & $-2,58 \%$ & $2,32 \%$ & $1,15 \%$ \\
\hline Dia após Renúncia do Presidente do Conselho de Administração & $02 / 03 / 20$ & $-8,74 \%$ & $0,81 \%$ & $2,36 \%$ \\
\hline $\begin{array}{l}\text { Berkshire Hathaway (empresa de Warren Buffett) divulga que não é } \\
\text { acionista do IRB }\end{array}$ & $03 / 03 / 20$ & $-7,72 \%$ & $-2,24 \%$ & $-1,02 \%$ \\
\hline $\begin{array}{l}\text { IRB comunica a revisão da base societária em participação da } \\
\text { Berkshire Hathaway; IRB comunica renúncia do Presidente da } \\
\text { companhia; IRB convida para teleconferências em 05/03/20 }\end{array}$ & $04 / 03 / 20$ & $-31,98 \%$ & $-0,96 \%$ & $1,60 \%$ \\
\hline IRB faz teleconferência com acionistas & $05 / 03 / 20$ & $-16,18 \%$ & $-4,68 \%$ & $-4,65 \%$ \\
\hline $\begin{array}{l}\text { IRB comunica instauração de Fiscalização Especial pela SUSEP, por } \\
\text { insuficiência de ativos garantidores }\end{array}$ & $11 / 05 / 20$ & $-14,84 \%$ & $-1,27 \%$ & $-1,49 \%$ \\
\hline $\begin{array}{l}\text { IRB demitiu o seu diretor de controladoria por justa causa de } \\
\text { "fraude em contratos". }\end{array}$ & $21 / 05 / 20$ & $-7,37 \%$ & $5,60 \%$ & $2,10 \%$ \\
\hline
\end{tabular}

Nota. * Data sem movimentação na bolsa (final de semana).

Fonte: Br.investing (2021). 
Lauren Dal Bem Venturini, Leonardo Flach, Jonatas Dutra Sallaberry e Luísa Karam de Mattos

\section{NOTAS DE ENSINO}

\subsection{OBJETIVOS EDUCACIONAIS DO CASO}

Este caso de ensino pode ser aplicado em cursos de graduação, pós-graduação e especialização nas disciplinas que abordem contabilidade, mercado de capitais, avaliação de empresas e negócios, finanças corporativas e contabilidade atuarial ou de seguros. Nesse contexto, espera-se que o discente, por meio de um caso real, desenvolva compreensão sobre as premissas envolvidas no processo de avaliação de empresas, para tanto, considerando os eventos contingenciais, particularidades setoriais, macroeconômicas, decisões estratégicas e relatórios administrativos e financeiros das empresas. Eventos pandêmicos semelhantes à Covid-19 são raros, mas crises e contingências regionais são comuns na história nacional e global demandando capacidade do futuro profissional distinguir diferentes causas e efeitos para a tomada de decisões (Almeida et al., 2019; Bataglin \& Alem, 2014; Valle et al., 2016). Ademais, espera-se aprimorar o senso crítico sobre erros e acertos protagonizados pelas companhias e que influenciam no seu valuation, bem como refletir sobre os efeitos do dólar e da Covid-19 nos negócios do IRB. Neste contexto, gera-se oportunidade para uma maior integração entre a teoria e a prática.

\subsection{FONTES DE OBTENÇÃO DE DADOS}

As informações foram obtidas por meio de dados secundários, como relatórios e demonstrações financeiras divulgados no portal da empresa e da B3. Assim, este caso para ensino baseia-se em problemas reais, dramatizado com narrativas fictícias e adaptando alguns cargos dos personagens para a preservação da identidade pessoal.

\subsection{PLANO DE ENSINO}

Para a discussão, é recomendada a leitura prévia do caso anteriormente à aula de sua aplicação, bem como instigar os discentes a verificarem notícias atualizadas divulgadas pela mídia sobre o IRB. A leitura preliminar de conceitos teóricos não se faz necessária, contudo se o docente entender que é preciso, alguns textos são sugeridos nas referências deste caso de ensino. Além do mais, o professor/instrutor pode solicitar aos alunos que respondam a determinadas questões para assegurar a leitura do caso e/ou solicitar que avancem na resolução do caso, por exemplo, avaliando os dados financeiros dos Anexos.

Quanto a aplicação do caso, sugere-se um debate inicial em pequenos grupos de alunos ( 2 a 4 discentes) para reflexão das possíveis respostas aos quatro questionamentos do caso de ensino e, posteriormente a discussão em plenária. A busca por soluções concretas e discussão parcial dos problemas tende a tornar a reflexão e aprendizagem mais significativa, sendo que o estudante entre seus pares tende a tornar-se mais empoderado para expor suas possíveis soluções e opiniões, construindo coletivamente as respostas para o debate no grande grupo (toda a turma). Por fim, o professor pode concluir a análise, mapeando as indicações dos alunos em conexão com as concepções teóricas. Na Tabela 3 sugere-se tempo médio para análise, discussão e encerramento do caso. 
Eventos noticiados sobre o IRB Brasil Resseguros S.A. e os efeitos no seu valuation

Tabela 3 - Sugestão de tempo médio para aplicação do caso para ensino

\begin{tabular}{l|c}
\multicolumn{1}{c|}{ Atividade } & Duração (minutos) \\
\hline Apresentação do caso e das atividades propostas & 5 a 10 \\
\hline Debate das questões propostas do caso para ensino (seção 6) em pequenos grupos & 15 a 25 \\
\hline Debate das questões propostas do caso para ensino (seção 6) no grande grupo & 40 a 50 \\
\hline Fechamento das discussões referentes às questões propostas no caso para ensino & 10 a 15 \\
\hline
\end{tabular}

Fonte: elaborada pelos autores.

\section{SUGESTÕES DE QUESTÕES}

6.1 QUESTÃO 1 - NA CONDIÇÃO DE ACIONISTA DO IRB, AVALIE AS REAIS CAUSAS DA QUEDA DO VALOR DAS AÇÕES DA COMPANHIA, SEGREGANDO ENTRE ASPECTOS EXTERNOS (POR EXEMPLO, COVID-19) E INTERNOS, DESTACANDO AS FALHAS E FATORES QUE MITIGAM A PERDA DE VALOR DE MERCADO.

A questão visa promover percepção do discente sobre aspectos que afetam o valor de mercado de uma companhia, de modo a diferenciar estratégias e decisões organizacionais de fatores macroeconômicos e contingenciais.

A Covid-19 pela sua forma de contágio exigiu que as pessoas ficassem isoladas, na maior parte dos casos em casa, o que resultou em significativa redução da produção e do consumo. Esse fato, de forma ampla, gerou queda do PIB dos países, mas individualmente redução da atividade das organizações, fechamento de empresas e demissão de trabalhadores. Analisando, especificamente, as linhas de negócios do IRB (Anexo 4 e descrição do caso), verifica-se que vários setores sofreram impactos, como o aéreo e de turismo.

O patrimônio também é severamente afetado pela alteração do câmbio das moedas estrangeiras, de modo que a forte depreciação do real aumenta o valor das obrigações expostas a outras moedas (Flores \& Miguita, 2020).

Outros eventos locais afetaram a perda de valor das ações do IRB. Entre o preço de abertura em 18 de fevereiro até 15 de maio, houve perda de $81,5 \%$ do valor de mercado, enquanto o Ibovespa recuou $32,7 \%$. Também vários fatos promoveram desconfiança nos investidores. As indagações da gestora Squadra sobre o resultado do IRB provocou queda do preço de ações, alertando o mercado. A estratégia do IRB de inicialmente negar a renúncia do presidente do Conselho de Administração e dias depois confirmar a sua saída, levantou suspeitas, pois a CVM exige comunicação ao mercado na data inicial.

O fato de a companhia sustentar sem evidências a ideia veiculada na mídia de que Buffet teria comprado suas ações, ocasionou incerteza ao mercado, podendo ser considerado frustrante pelos investidores e negligência com o uso dos recursos alheios. Dessa forma, é possível associar e discutir aspectos éticos a divulgação de informações. A companhia deveria ter realizado conferências e comunicações igualitárias sobre os questionamentos da Squadra para todos os investidores, sem privilégio para alguns. Por fim, o anúncio de fiscalização especial da Susep, por insuficiência de provisões, e a demissão de um diretor por possíveis fraudes intrigou o mercado.

Investidores delegam aos analistas financeiros a função de entender as estratégias de divulgação dos gestores e de interpretar os demonstrativos contábeis, realizando intermediação e recomendação de investimentos, o que reduz a assimetria informacional. Outra possibilidade de reduzir assimetria relacionada ao reconhecimento da variação cambial seria a de as companhias utilizarem as notas explicativas das demonstrações financeiras para deixar claro a investidores, analistas e "curiosos" em geral quais são os 
Lauren Dal Bem Venturini, Leonardo Flach, Jonatas Dutra Sallaberry e Luísa Karam de Mattos

desdobramentos da perda da variação cambial no passado, no curto e no longo prazo (Sescon/RJ, 2020). Ainda, o avanço da tecnologia permite que as informações circulem rapidamente e provoquem correção quase instantânea no valor das ações. Portanto, é importante as companhias refletirem sobre as questões éticas, seja na divulgação de informações financeiras ou não ao mercado, tendo em vista o reflexo que isso denota em seu valuation.

Algumas idiossincrasias do IRB podem sustentar apreciação pelos acionistas mitigando queda ainda maior nos valores, como: listagem no novo mercado da B3 - maior índice de governança; atividade econômica desenvolvida; tradição no mercado e principalmente por ser auditada por big four. A auditoria é caracterizada pela verificação da integridade dos relatórios financeiros por parte independente à preparação, assegurando que os gestores usaram regras e princípios contábeis de maneira consistente ao longo do tempo e que foram empregadas estimativas contábeis razoáveis (Palepu \& Healy, 2016).

\subsection{QUESTÃO 2 - A SUSEP QUESTIONA A FALTA DE ATIVOS REGULATÓRIOS COMPENSANDO O PASSIVO. O IRB EXPLICA QUE ISSO FOI OCASIONADO PELO DÓLAR E A COVID-19. AS DEMONSTRAÇÕES FINANCEIRAS DO IRB (ANEXOS 2 E 3) NÃO REPORTAM PRESENÇA DE HEDGE. COMO A CONTRATAÇÃO DE HEDGE PODERIA PROTEGER O IRB? QUAIS HEDGES PODERIAM TER SIDO CONTRATADOS?}

A questão fomenta debate sobre os mecanismos de proteção, denominados de hedge, e se o IRB deveria os contratar.

Conforme balanço patrimonial (Anexos 2 a 4), 37\% das provisões técnicas estão no exterior, sendo a maioria em dólar. Já os ativos de cobertura (exterior) representam $13 \%$ dos passivos, abaixo da média da empresa (total 39\%). Logo, o IRB revela significativa exposição de suas provisões técnicas à variação cambial. No momento da indenização futura do sinistro, mantida uma elevada variação cambial, o segurador precisará de maior quantidade de reais para saldar suas obrigações. Uma posição em ativos na mesma moeda ou contratos de aquisição de moeda estrangeira em cotação compatível com o negócio original evitaria essa necessidade de maior capital para cobrir os sinistros.

O hedge é um instrumento de tomada de decisões que diminui o risco de volatilidade dos retornos de uma entidade (Silva, 2014). Diante disso, existem duas possíveis classificações: hedge econômico e hedge accounting. O primeiro visa reduzir exposições a diversos riscos, como taxa de juros, risco cambial, oscilações de preços em geral, entre outros. O hedge accounting é uma metodologia contábil que busca reduzir as variações geradas nos resultados contábeis ocasionadas por hedges econômicos. Ainda, pode-se destacar o hedge natural, onde a empresa ou o investidor não precisa tomar nenhuma ação para se proteger da variação no preço de algum ativo ou passivo. Em geral, essa situação ocorre quando o ativo e o passivo de determinada empresa sofrem impactos em direções contrárias. Por exemplo, uma companhia que detêm as receitas e despesas dolarizadas, havendo alta no dólar, terá um impacto positivo nas receitas e negativo nas despesas. Logo, essa empresa não necessita adquirir nenhum derivativo ou instrumento financeiro de hedge.

Neste âmbito, o IRB possui operações no exterior, o que expõe a entidade ao risco de alteração no valor justo ou nos fluxos de caixa futuros. Com isso, poderia ter contratado operações de hedge que deveriam ser registradas no Balanço Patrimonial, Demonstração do Resultado e Notas Explicativas. Por meio de contratos de hedge cambial, o IRB poderia travar o preço do dólar para data futura, garantindo uma previsibilidade de valor e consequente segurança para sua liquidez. Por outro lado, no tocante a avaliação de empresas, é preciso 
que os investidores compreendam os efeitos do hedge nos relatórios financeiros, especialmente no contexto da pandemia (Baldwin \& Di Mauro, 2020). O estudo de Fonseca et al. (2017) analisou o fato de os bancos brasileiros adotarem o hedge accounting, revelando sua capacidade de aumentar a persistência dos lucros.

\subsection{QUESTÃO 3 - A GESTÃO DO IRB INDUZ QUE O PROBLEMA QUESTIONADO PELA SUSEP SE TRATA "MERAMENTE DE PREJUÍZO CONTÁBIL", ELEVAÇÃO DO PASSIVO DEVIDO À SENSIBILIDADE DO DÓLAR À PANDEMIA DE COVID-19. VOCÊ CONCORDA COM ESSA AFIRMAÇÃO? JUSTIFIQUE.}

A questão busca provocar reflexão sobre interpretações equivocadas aos resultados dos negócios, atrelando a fatos comuns em crises financeiras e cambiais.

Inicialmente, é oportuno refletir sobre a impropriedade da expressão "meramente prejuízo contábil" visto que a Contabilidade tem por objetivo refletir os eventos econômicofinanceiros que ocorrem com a empresa. Ela não 'cria' fatos, mas evidencia os reflexos patrimoniais das decisões de gestão no patrimônio da empresa, de acordo com as normas legais. Além do mais, as demonstrações financeiras contribuem para que os usuários externos consigam analisar a gestão e questionar sobre determinadas decisões.

O IRB possui atuação em Buenos Aires e Londres, portanto, isso pressupõe que suas operações financeiras são impactadas pela elevação do dólar e desvalorização do real. 0 Anexo 4 evidencia existência de mais passivos do que ativos no exterior (em tese, queda do dólar seria pior). Se equivalentes, seria o famoso "hedge natural". São 37\% (R\$ 3.443 milhões de R\$ 9.169 milhões) de provisões técnicas no exterior, ou seja, expostos à variação cambial, frente aos ativos de cobertura no exterior de 13\% (R\$ 453 milhões) dos passivos. Se o Covid-19 afetar as operações e provocar uma demanda no exterior (uso dos seguros) em curto prazo exigindo o resgate de outras aplicações antes do prazo ou a liquidação de ativos durante a crise, acarretará em risco de liquidez argumentado pela Susep.

Não há destaque nas demonstrações financeiras sobre a contratação de hedge. O IRB apenas justifica os questionamentos da Squadra e da CVM com o fato da Covid-19 ter afetado as suas atividades, mas não fornece detalhes desse efeito. Loughran e McDonald (2020) explicitam que, por meio das divulgações periódicas, os administradores têm a obrigação de informar aos acionistas existentes e potenciais sobre quaisquer riscos razoáveis que possam afetar o valor das ações. Assim, às partes interessadas, o impacto do Covid-19 deveria ser evidenciado com informações financeiras acompanhadas de dados descritivos. Para evidenciar os riscos de queda da receita, ativos não recuperáveis, gerenciamento de riscos empresariais (aspectos financeiros ou não) há documentos que acompanham ou são partes dos relatórios financeiros, como Notas Explicativas, releases, Formulário de Referência e Relatório da Administração.

Portanto, os números contábeis serão informativos ao mercado se retratarem a verdadeira situação da companhia, ou seja, estiverem livres de gerenciamentos de resultados. No entanto, conforme ValorInveste (2020), na dúvida entre dois caminhos, pode ocorrer de o gestor optar por aquele que reduz o lucro a ser reconhecido, de modo a acelerar ou adiar o reconhecimento de alguma receita ou despesa. Isso é conhecido como gerenciamento de resultados, que é a liberdade em mudar o tempo dos registros contábeis, mas sempre no limite do que preveem as normas, e sob o escrutínio do auditor externo e que no longo prazo haverá convergência entre lucro e fluxo de caixa.

Ramelli e Wagner (2020) declaram que as preocupações dos investidores devido à pandemia voltam-se às dívidas e à liquidez corporativa. Com isso, é importante esclarecer 
Lauren Dal Bem Venturini, Leonardo Flach, Jonatas Dutra Sallaberry e Luísa Karam de Mattos

aos acionistas qual o choque real e a incerteza dos negócios causados pelo surto de Covid19 , visto que os canais de comunicação podem veicular afirmações gerais dos efeitos no setor. Faz-se necessário revisar as contas patrimoniais para que representem a atual situação financeira da companhia. Desta forma, a Contabilidade precisa respaldar os saldos efetivos de recebíveis, das perdas estimadas de sinistros, bem como dos resgates de seguros.

O resultado de 2019 foi auditado e não evidencia a contratação de hedge, além de apresentar ativos no exterior que são inferiores ao passivo, ou seja, envolve um contexto de gestão e não apenas reflexos de ajustes contábeis decorrentes de operações que não afetam o caixa diretamente. 0 hedge discutido na questão anterior poderia proteger a posição patrimonial dos passivos e despesas estimadas.

6.4 QUESTÃO 4 - CONSIDERANDO O HISTÓRICO E AS PROJEÇÕES FUTURAS DO IRB, LISTE ASPECTOS ORGANIZACIONAIS E MACROECONÔMICOS QUE AFETAM O VALUATION DESSA COMPANHIA.

A questão busca promover reflexão dos alunos, podendo assumir a posição de investidor ou analista, sobre o valuation do IRB. Para essa questão, o docente pode considerar também aspectos já salientados e analisados nas questões anteriores.

A Squadra aponta que o IRB tem lucro, contudo não apresenta o que seria o real desempenho econômico da seguradora. A gestora de investimentos é apontada como interessada na queda do valor das ações da seguradora por conta da gestão de seus negócios.

Os relatórios da seguradora apresentam projetos de expansão, investimentos em tecnologia e exploração de novos comportamentos dos consumidores de seguros que podem gerar cenários de aumento de faturamento e redução de custos. Ademais, destaca ser uma empresa ágil para criar produtos e serviços, que além de apoiar o desenvolvimento de negócios por fintechs, construtechs, healthtechs, logtechs e big techs, podem favorecer a transformação do negócio num ambiente contingencial, como o causado pela Covid-19.

O IRB apresentou inicialmente perspectivas positivas para 2020 , com potencial de evolução especialmente no agronegócio, crescimento do setor de óleo e gás, além do desempenho acima do PIB. Alguns segmentos de mercado como o agronegócio e combustíveis possuem forte influência de preços determinados por commodities, podendo a desvalorização do real apresentar efeitos positivos.

Mais oportunidades decorrem da eliminação da obrigatoriedade de apólices anuais de seguros, determinada pela Susep em agosto de 2019, o que permite a criação de produtos mais flexíveis para os quais o IRB menciona estar preparado. 0 ambiente de desregulação estatal no Brasil aliado a flexibilização de regras e incentivos estatais para enfrentamento dos efeitos econômicos da Covid-19 também pode favorecer o desempenho do IRB.

A própria pandemia possivelmente antecipou o planejamento de melhorias na área tecnológica, pois para impedir ou mitigar a disseminação do Covid-19, os governos instituíram o distanciamento social e quarentenas. Isso impacta a força de trabalho, obrigando as empresas a instituírem o home office e elevando gastos em tecnologia e logística.

A pandemia do Covid-19 provocará impacto positivo em alguns segmentos como saúde, tecnologia, entretenimento por streaming, por exemplo, empresas como Amazon, Clorox, Netflix e Zoom Vídeo Communications, embora a grande maioria tenha sofrido um 
declínio acentuado no preço de suas ações. Portanto, a Covid-19 pode ter influenciado outros setores a buscarem maior proteção de seus negócios além de ampliar à busca das seguradoras por mais operações de resseguro.

Cheema-Fox et al. (2020) destacam que a crise do Covid-19 pode atenuar a desconfiança dos investidores durante o colapso do mercado. Reforçam ainda que, em um período de volatilidade e crise, a forma como a empresa responde à crise pode aumentar a confiança dos investidores e fazer com que seja mais eficiente ao choque do mercado. Dessa forma, a maneira como as organizações reposicionam suas operações e produtos, provavelmente, serão considerações importantes pelas partes interessadas e que refletirão na avaliação do mercado para precificar e regulamentar o comportamento das ações.

Tais fatos geram uma expectativa de redução do risco do negócio e podem renovar a credibilidade do IRB e, por consequência, retomar a valorização da companhia e de suas ações no mercado de capitais. Ainda, a nova gestão da companhia pode divulgar novos projetos, bem como esclarecer os apontamentos da gestora Squadra retomando o crescimento empresarial. Ao se observar a Tabela 2, também se pode compreender que a crise de confiança dos investidores do IRB pode ser passageira, de modo que atitudes positivas possibilitam melhorar a crise de imagem. Esse progresso pode ser devido a importância que a atividade do IRB tem no mercado nacional brasileiro.

Por outro lado, esses eventos positivos podem não acontecer e as ações do IRB continuarem perdendo valor. Os projetos novos em tecnologia podem não obter o sucesso esperado em um ambiente de negócios ainda mais concorrido, enquanto novos comportamentos dos consumidores de seguros podem ser transitórios, e abandonados à medida que retomem a rotina tradicional. O agronegócio pode sentir mais fortemente os efeitos do aumento do dólar nos insumos para a nova safra, frente à eventual redução do dólar (ao menos um percentual eventualmente artificial das elevações anteriores).

A eliminação da obrigatoriedade de apólices anuais de seguros também traz riscos de 'infidelidade' do cliente, possível atratividade a novos concorrentes pela valorização dólar, e uma infraestrutura para home office desenvolvida no início da pandemia podem frustrar as expectativas de sucesso nos novos projetos e de melhores resultados nos períodos seguintes. Portanto, é importante reforçar que o mercado responde rapidamente as notícias e, dependendo do teor, as reações podem impactar positivamente ou negativamente no valuation da empresa. Cabe então, a reflexão que a ética empresarial se faz relevante no ambiente de negócios.

\section{REFERÊNCIAS}

Almeida, I. M. D., Jackson Filho, J. M., \& Vilela, R. A. D. G. (2019). Razões para investigar a dimensão organizacional nas origens da catástrofe industrial da Vale em Brumadinho, MG, Brasil. Cadernos de Saúde Pública, 35.

Baldwin, R., \& Di Mauro, B. W. (2020). Mitigating the COVID economic crisis: Act fast and do whatever it takes. VoxEU.org eBook.

Bataglin, L. M. C., \& Alem, D. (2014). O problema de localização-distribuição no mega desastre da região Serrana no Rio de Janeiro. Gestão \& Produção, 21(4), 865-881. 
Lauren Dal Bem Venturini, Leonardo Flach, Jonatas Dutra Sallaberry e Luísa Karam de Mattos

Br.Investing (2021). Índices. Recuperado em 10 de setembro, 2021, de: https://br.investing.com/indices/.

Cheema-Fox, A., LaPerla, B. R., Serafeim, G., \& Wang, H. (2020). Corporate Resilience and Response During Covid-19. Working Paper, available at SSRN: http://dx.doi.org/10.2139/ssrn.3578167.

Comissão de Valores Mobiliários - CVM. (2020). Notas Explicativas as Demonstrações Contábeis do exercício de 2019 do IRB-Brasil. Recuperado em 18 de maio, 2020, de: https://www.rad.cvm.gov.br/ENETCONSULTA/frmGerenciaPaginaFRE.aspx?NumeroSeq uencialDocumento $=91057 \&$ CodigoTipolnstituicao $=2$

Comissão de Valores Mobiliários - CVM. (2020). Prospecto definitivo da oferta pública de distribuição. Recuperado em 09 de junho, 2020, de:

http://www2.bmfbovespa.com.br/empresas/consbov/ArquivoComCabecalho.asp?motiv $\mathrm{o}=\&$ protocolo $=572952 \&$ funcao $=$ visualizar $\&$ site $=\mathrm{B}$.

Comissão de Valores Mobiliários - CVM. (2020). Relatório da Administração sobre as Demonstrações Contábeis de 2019 do IRB-Brasil. Recuperado em 18 de maio, 2020, de: https://www.rad.cvm.gov.br/ENETCONSULTA/frmGerenciaPaginaFRE.aspx?NumeroSeq uencialDocumento=91057\&CodigoTipolnstituicao $=2$.

Deng, S. Q., \& Peng, H. J. (2020). Characteristics of and public health responses to the coronavirus disease 2019 outbreak in China. Journal of Clinical Medicine, 9(2), 575.

Flores, E. \& Miguita, D. (2020). Demonstrações contábeis e Covid-19. Valor Econômico, 21(4994), p.E32.

Fonseca, W. S. V., Galdi, F. C., \& Hartwig, A. (2019). A adoção de hedge accounting e a persistência dos resultados divulgados pelos bancos em atuação no mercado brasileiro. Contabilidade Vista \& Revista, 30(3), 106-127. https://doi.org/10.22561/cvr.v30i3.4984.

InfoMoney. (2020). Berkshire Hathaway, de Buffett, nega ter ações do IRB Brasil.

Recuperado em 11 de setembro, 2021, de:

https://www.infomoney.com.br/mercados/berkshire-hathaway-de-buffett-nega-teracoes-do-irb-brasil/.

InfoMoney. (2020a). IRB lucra R\$ 1,76 bilhão em 2019 e contrata EY para segunda auditoria [...]. Recuperado em 12 de setembro, 2021, de:

https://www.infomoney.com.br/mercados/irb-lucra-r-176-bilhao-em-2019-e-contrataey-para-nova-auditoria-mais-balancos-e-outros-destaques-no-radar/.

IRB Brasil RE. (2020). Comunicado ao Mercado (04/03). Recuperado em 20 de maio, 2020, de https://mz-filemanager.s3.amazonaws.com/0d797649-90df-4c56-aa01-

6ee9c8a13d75/aviso-aos-acionistas-comunicados-fato-relevantecentral-dedownloads/f375e8c8135df0d8deba2046dd8c53342c0f75854d5f5f9401bb3c9091232e1 b/comunicado_ao_mercado_convocacao_teleconferencia.pdf. 
IRB Brasil RE. (2020). Comunicado ao Mercado (28/02). Recuperado em 20 de maio, 2020, de https://mz-filemanager.s3.amazonaws.com/0d797649-90df-4c56-aa016ee9c8a13d75/aviso-aos-acionistas-comunicados-fato-relevantecentral-dedownloads/59324685661039ad300c2e43840226b26f685b3dea457d0ea6d47f1970a178 10/comunicado_ao_mercado_renuncia_ivan_monteiro.pdf.

IRB Brasil RE. (2020). Fato Relevante (03/03). Recuperado em 20 de maio, 2020, de: https://mz-filemanager.s3.amazonaws.com/0d797649-90df-4c56-aa016ee9c8a13d75/aviso-aos-acionis tas-comunicados-fato-relevantecentral-dedownloads/48d58335cd0ef1c2b225a0840d09dc6 346fa837376c285adfabc01ee9adb0553/.

IRB Brasil RE. (2020). Fato Relevante (11/05). Recuperado em 20 de maio, 2020, de: https://apicatalog.mziq.com/filemanager/v2/d/0d797649-90df-4c56-aa016ee9c8a13d75/05ce0d4e-3497-0d7b-b3a8-f77ba950f61e?origin=2.

IRB Brasil RE. (2020). Fato Relevante (27/02). Recuperado em 20 de maio, 2020, de: https://mz-filemanager.s3.amazonaws.com/0d797649-90df-4c56-aa016ee9c8a13d75/aviso-aos-acionistas-comunicados-fato-relevantecentral-de-downloads/.

IRB Brasil RE. (2020). Quem somos. Recuperado em 18 de maio, 2020, de: https://www.irbre.com/PT-BR/Paginas/default.aspx.

Loughran, T. \& McDonald, B. (2020). Management Disclosure of Risk Factors and Covid-19. Working Paper. available at SSRN: http://dx.doi.org/10.2139/ssrn.3575157.

Palepu, K. G., \& Healy, P. M. (2016). Análise e Avaliação de Empresas: decisões e valuation usando demonstrativos financeiros. São Paulo: Cengage Learning.

Ragazzi, A. P. (2020). IRB Re demite contador por justa causa. Valor Econômico. Recuperado em 28 de maio, 2020, de: https://valor.globo.com/financas/noticia/2020/05/22/irbbrasil-re-demite-contador-por-justa-causa.ghtml.

Ramelli, S. \& Wagner, A. F. (2020). Feverish Stock Price Reactions to Covid-19. Working Paper, available at SSRN: http://dx.doi.org/10.2139/ssrn.3550274

Sescon/RJ. (2020). O 'meramente contábil' ataca nos balanços novamente. Recuperado em 11 de setembro, 2021, de: https://sescon-rj.org.br/2020/05/20/o-meramente-contabilataca-nos-balancos-novamente/\#.

Silva, F. C. (2014). Hedge accounting no Brasil. Tese de Doutorado. Universidade de São Paulo.

Squadra Investimentos. (2020). Carta de esclarecimentos aos cotistas, de 09 de fevereiro de 2020. Recuperado em 18 de maio, 2020, de:

http://www.squadrainvestimentos.com/pdf/esclarecimentos-2019.pdf. 
Lauren Dal Bem Venturini, Leonardo Flach, Jonatas Dutra Sallaberry e Luísa Karam de Mattos

Squadra Investimentos. (2020). Relatório de análise da Squadra sobre o IRB-Brasil Resseguros S.A., de 02 de fevereiro de 2020. Recuperado em 18 de maio, 2020, de: http://www.squadrainvestimentos.com/pdf/relatorio-2019.pdf.

Valle, D., Pimenta, D. N., \& Aguiar, R. (2016). Zika, dengue e chikungunya: desafios e questões. Epidemiologia e Serviços de Saúde, 25, 419-422.

ValorInveste. (2020). Investir é tomar decisão sobre dinheiro em terreno movediço. Recuperado em 11 de setembro, 2021, de:

https://valorinveste.globo.com/blogs/fernando-torres/post/2020/02/investir-e-tomardecisao-sobre-dinheiro-em-terreno-movedico.ghtml. 
Eventos noticiados sobre o IRB Brasil Resseguros S.A. e os efeitos no seu valuation

ANEXO 1 - Demonstração do resultado do exercício para tomada de decisões

\begin{tabular}{|l|r|r|}
\hline \multicolumn{1}{|c|}{ Descrição do Fato } & \multicolumn{1}{|c|}{$\mathbf{2 0 1 9}$} & $\mathbf{2 0 1 8}$ \\
\hline Prêmios Emitidos & $\mathbf{8 . 5 1 5 . 4 6 7}$ & $\mathbf{6 . 9 6 3 . 8 6 8}$ \\
\hline Prêmios de resseguros país & 4.826 .104 & 4.219 .742 \\
\hline Prêmios de resseguros exterior & 3.689 .363 & 2.744 .126 \\
\hline Prêmios cedidos em retrocessão & $(2.208 .485)$ & $(1.869 .978)$ \\
\hline Prêmios retidos & $\mathbf{6 . 3 0 6 . 9 8 2}$ & $\mathbf{5 . 0 9 3 . 8 9 0}$ \\
\hline Variações das provisões técnicas & $(633.248)$ & $(296.755)$ \\
\hline Prêmios ganhos & $\mathbf{5 . 6 7 3 . 7 3 4}$ & $\mathbf{4 . 7 9 7 . 1 3 5}$ \\
\hline Sinistros retidos & $(2.898 .121)$ & $(2.682 .750)$ \\
\hline PSL & $(2.634 .448)$ & $(2.260 .073)$ \\
\hline IBNR & $(263.673)$ & $(422.677)$ \\
\hline Custo de aquisição & $(1.126 .537)$ & $(906.642)$ \\
\hline Outras despesas operacionais & $(117.314)$ & $(38.143)$ \\
\hline Resultado de underwriting & 1.531 .762 & $\mathbf{1 . 1 6 9 . 6 0 0}$ \\
\hline Despesas administrativas & $(283.102)$ & $(228.181)$ \\
\hline Despesas com tributos & $(113.249)$ & $(133.837)$ \\
\hline Resultado financeiro e patrimonial & 776.857 & 705.974 \\
\hline Resultado financeiro & 733.615 & 628.897 \\
\hline Resultado patrimonial & 43.242 & 77.077 \\
\hline Resultado antes dos impostos & 1.912 .268 & $\mathbf{1 . 5 1 3 . 5 5 6}$ \\
\hline Impostos, contribuições e participação nos lucros & $(148.732)$ & $(294.760)$ \\
\hline Lucro líquido do exercício & $\mathbf{1 . 7 6 3 . 5 3 6}$ & $\mathbf{1 . 2 1 8 . 7 9 6}$ \\
\hline
\end{tabular}

Nota: PSL (Provisões de Sinistros a Liquidar) reflete os avisos de sinistros que a Companhia recebeu no período; IBNR (Incurred But Not Reported) é uma provisão atuarial em bases estatísticas para futuros avisos de sinistro.

Fonte: relatório de administração do IRB Brasil RE (2020). 
Lauren Dal Bem Venturini, Leonardo Flach, Jonatas Dutra Sallaberry e Luísa Karam de Mattos

ANEXO 2 - Ativo patrimonial consolidado

\begin{tabular}{|c|c|c|c|c|}
\hline Conta & Descrição & 2019 & 2018 & 2017 \\
\hline 1 & Ativo Total & 17.174 .255 & 15.940 .434 & 14.343 .210 \\
\hline 1.01 & Ativo Circulante & 10.984 .936 & 10.374 .000 & 8.330 .491 \\
\hline 1.01 .01 & Caixa e Equivalentes de Caixa & 35.864 & 43.131 & 25.771 \\
\hline 1.01 .02 & Aplicações Financeiras & 1.232 .818 & 2.595 .474 & 1.596 .357 \\
\hline 1.01.02.01 & Aplicações Financeiras Avaliadas a Valor Justo & 1.232 .818 & 2.595 .474 & 1.310 .624 \\
\hline 1.01.02.01.01 & Títulos para Negociação & 995.831 & 2.371 .374 & 1.194 .064 \\
\hline 1.01.02.01.02 & Títulos Designados a Valor Justo & 236.987 & 224.100 & 116.560 \\
\hline 1.01 .02 .02 & Aplicações Financeiras Avaliadas a Valor Justo & 0 & 0 & 285.733 \\
\hline 1.01 .03 & Créditos das Operações & 5.476 .120 & 4.491 .002 & 3.220 .012 \\
\hline 1.01.03.01 & Seguros e Resseguros & 5.476 .120 & 4.491 .002 & 3.220 .012 \\
\hline 1.01.03.01.01 & Operações com Seguradoras & 3.820 .914 & 3.144 .749 & 2.216 .855 \\
\hline 1.01.03.01.02 & Operações com Resseguradoras & 1.501 .561 & 1.289 .585 & 937.982 \\
\hline 1.01.03.01.03 & Outros Créditos Operacionais & 153.645 & 56.668 & 65.175 \\
\hline 1.01 .04 & Títulos e Créditos a Receber & 542.444 & 111.703 & 149.678 \\
\hline 1.01 .07 & Despesas Antecipadas & 8.677 & 11.886 & 6.103 \\
\hline 1.01 .08 & Despesas de Comercialização Diferidas & 93.044 & 65.197 & 57.633 \\
\hline 1.01 .09 & Outros Ativos Circulantes & 3.595 .969 & 3.055 .607 & 3.274 .937 \\
\hline 1.01 .09 .03 & Outros & 3.595 .969 & 3.055 .607 & 3.274 .937 \\
\hline 1.02 & Ativo Não Circulante & 6.189 .319 & 5.566 .434 & 6.012 .719 \\
\hline 1.02 .01 & Ativo Realizável em Longo Prazo & 5.900 .218 & 4.876 .247 & 5.403 .901 \\
\hline 1.02.01.01 & Aplicações Financeiras Avaliadas a Valor Justo & 3.630 .946 & 3.366 .388 & 4.219 .705 \\
\hline 1.02.01.04 & Créditos das Operações & 2.230 .349 & 1.475 .917 & 1.130 .418 \\
\hline 1.02.01.04.01 & Títulos e créditos a receber & 887.150 & 398.086 & 108.544 \\
\hline 1.02.01.04.02 & Créditos tributários e previdenciários & 44.713 & 38.643 & 57.868 \\
\hline 1.02 .01 .04 .03 & Ativo fiscal diferido & 603.901 & 386.215 & 335.770 \\
\hline 1.02.01.04.04 & Depósitos judiciais e fiscais & 694.585 & 652.973 & 628.236 \\
\hline
\end{tabular}

Fonte: adaptado de CVM (2020). 
Eventos noticiados sobre o IRB Brasil Resseguros S.A. e os efeitos no seu valuation

ANEXO 3 - Passivo patrimonial consolidado

\begin{tabular}{|c|c|c|c|c|}
\hline Conta & Descrição & 2019 & 2018 & 2017 \\
\hline 2 & Passivo Total & 17.174 .255 & 15.940 .434 & 14.343 .210 \\
\hline 2.01 & Passivo Circulante & 11.300 .651 & 10.859 .175 & 9.730 .998 \\
\hline 2.01 .01 & Contas a Pagar & 519.124 & 391.450 & 238.462 \\
\hline 2.01 .02 & Débitos de Operações & 1.508 .623 & 1.393 .070 & 1.252 .165 \\
\hline 2.01.02.01 & Seguros e Resseguros & 1.508 .623 & 1.393 .070 & 1.252 .165 \\
\hline 2.01.02.01.01 & Operações com seguradoras & 2.095 & 251 & 606 \\
\hline 2.01.02.01.02 & Operações com resseguradoras & 1.355 .491 & 1.251 .262 & 1.137 .443 \\
\hline 2.01.02.01.03 & Corretores de resseguros e retrocessões & 143.981 & 106.099 & 83.029 \\
\hline 2.01.02.01.04 & Outros débitos operacionais & 7.056 & 35.458 & 31.087 \\
\hline 2.01 .03 & Depósitos de Terceiros & 336.409 & 427.425 & 166.766 \\
\hline 2.01 .04 & Provisões Técnicas & 8.936 .495 & 8.647 .230 & 8.073 .605 \\
\hline 2.01.04.01 & Seguros e Resseguros & 8.936 .495 & 8.647 .230 & 8.073 .605 \\
\hline 2.01.04.01.03 & Provisão de prêmios não ganhos & 2.904 .439 & 2.147 .178 & 1.836 .237 \\
\hline 2.01.04.01.04 & Sinistros a liquidar & 3.569 .627 & 4.222 .549 & 4.372 .552 \\
\hline 2.01.04.01.05 & Provisão de sinistros ocorridos mas não avisados & 2.232 .181 & 1.999 .068 & 1.687 .480 \\
\hline 2.01.04.01.06 & Outras Provisões & 230.248 & 278.435 & 177.336 \\
\hline 2.02 & Passivo Não Circulante & 1.232 .320 & 1.080 .479 & 1.031 .029 \\
\hline 2.02 .01 & Passivo Exigível a Longo Prazo & 1.232 .320 & 1.080 .479 & 1.031 .029 \\
\hline 2.02.01.01 & Contas a Pagar & 498.750 & 427.116 & 422.088 \\
\hline 2.02.01.02 & Débitos das Operações & 789 & 789 & 789 \\
\hline 2.02.01.03 & Provisões Técnicas & 232.662 & 158.665 & 130.670 \\
\hline 2.02 .01 .04 & Outros Passivos & 500.119 & 493.909 & 477.482 \\
\hline 2.03 & Patrimônio Líquido Consolidado & 4.641 .284 & 4.000 .780 & 3.581 .183 \\
\hline 2.03 .01 & Capital Social Realizado & 1.953 .080 & 1.953 .080 & 1.953 .080 \\
\hline 2.03 .02 & Reservas de Capital & -12.197 & -12.956 & -12.956 \\
\hline 2.03.02.05 & Ações em Tesouraria & -12.956 & -12.956 & -12.956 \\
\hline 2.03 .02 .08 & Reserva de capital & 759 & 0 & 0 \\
\hline 2.03 .04 & Reservas de Lucros & 2.891 .472 & 2.174 .037 & 1.717 .220 \\
\hline 2.03.04.05 & Reserva de Retenção de Lucros & 2.126 .970 & 1.595 .109 & 1.277 .821 \\
\hline 2.03.04.08 & Dividendo Adicional Proposto & 764.502 & 578.928 & 439.399 \\
\hline 2.03 .06 & Ajustes de Avaliação Patrimonial & -191.071 & -113.381 & -76.161 \\
\hline
\end{tabular}

Fonte: adaptado de CVM (2020). 
Lauren Dal Bem Venturini, Leonardo Flach, Jonatas Dutra Sallaberry e Luísa Karam de Mattos

ANEXO 4 - Ativos e passivos por linha de negócio - consolidado

\begin{tabular}{|c|c|c|c|c|}
\hline \multirow[t]{2}{*}{ Linha } & \multicolumn{2}{|c|}{ Passivo (Resseguro) } & \multicolumn{2}{|c|}{ Ativo (Retrocessão) } \\
\hline & 2019 & 2018 & 2019 & 2018 \\
\hline Aeronáuticos & 394.714 & 471.004 & $(332.876)$ & (376.253) \\
\hline Automóvel & 139.337 & 199.243 & $(13.267)$ & $(16.885)$ \\
\hline Habitacional & 47.175 & 53.778 & $(281)$ & (177) \\
\hline Marítimos & 122.819 & 176.223 & (47.596) & $(56.069)$ \\
\hline Nucleares & 16.680 & 15.623 & $(14.354)$ & $(13.837)$ \\
\hline Patrimonial & 2.106 .589 & 2.257 .948 & $(1.403 .993)$ & $(1.350 .592)$ \\
\hline Pessoas & 317.405 & 289.754 & $(63.830)$ & $(38.922)$ \\
\hline Petróleo & 609.473 & 317.307 & (430.679) & $(264.636)$ \\
\hline Responsabilidades & 405.795 & 634.240 & (265.099) & (348.926) \\
\hline Riscos financeiros & 394.389 & 465.929 & $(94.679)$ & $(109.509)$ \\
\hline Rural & 944.657 & 753.085 & $(360.255)$ & $(50.500)$ \\
\hline Transportes & 226.767 & 482.636 & (144.181) & $(260.967)$ \\
\hline Exterior & 3.443 .357 & 2.689 .125 & (453.917) & (197.179) \\
\hline Total & 9.169 .157 & 8.805 .895 & $(3.625 .007)$ & (3.084.452) \\
\hline
\end{tabular}

Fonte: notas explicativas do IRB Brasil RE (2020). 